\title{
Environmental Sustainability in the Context of Mass Personalisation - Quantification of the Carbon Footprint with Life Cycle Assessment
}

\author{
Ann-Kathrin Briem \\ Institute for Acoustics and Building Physics (IABP), University of Stuttgart, Germany \\ ann-kathrin.briem@iabp.uni-stuttgart.de \\ Thomas Betten \\ Institute for Acoustics and Building Physics (IABP), University of Stuttgart, Germany \\ Michael Held \\ Fraunhofer Institute for Building Physics, Stuttgart, Germany \\ Daniel Wehner \\ Fraunhofer Institute for Building Physics, Stuttgart, Germany \\ Michael Baumann \\ Fraunhofer Institute for Building Physics, Stuttgart, Germany
}

Received (10.11.2018.); Revised (29.03.2019); Accepted (8.04.2019.)

\begin{abstract}
Driven by individualisation as a trend and enabled by new production technologies and increasing digitalisation, mass customisation (MC) and mass personalisation (MP) open up new possibilities to address user demands much better. However, the sustainability achievements of current manufacturing technology could be compromised by this trend as variability in environmental impacts increases. Small lot sizes are likely to increase per piece manufacturing efforts, and reusability and recyclability might be limited. Nevertheless, personalised products can address user demands much better and hold great sustainability potential as well. In order to manage these risks and potentials, sustainability assessments are necessary. This paper first provides a short overview of the current state of sustainability assessment in the field based on existing literature and the current discussion in the scientific community. To contribute to filling the existing gap in the application of sustainability assessments by providing further quantitative results, Life Cycle Assessment (LCA) is applied to two conceptual MC/MP examples. Operationalised by the carbon footprint, the environmental impacts of customer choices are quantified for the analysed scenarios. The examples are within the field of mobility, one examining return logistics of personalised consumer products, the other analysing lowcarbon vehicle choices based on individual driving behaviour. The aim of this paper is to contribute to embedding LCA as a methodology for the assessment of environmental sustainability in the area of $M C$ and MP and add qualitative assessment to support existing sustainability frameworks in the field.
\end{abstract}

Key words: Environmental Sustainability, Example Scenarios, Life Cycle Assessment, LCA, Mass Customisation, Mass Personalisation, Passenger Transport, Return Logistics

\section{INTRODUCTION}

The way most products are manufactured changed significantly over time. This change becomes clear when looking at two parameters: the degree of process automation and the degree of product variety. While back in the 1800s custom-tailored products could be found on a broad scale but only afforded by few people (high variety, low automation), Henry Ford's production revolution started the shift to standardised products for the masses in the early 20th century (low variety, high automation). Recent advancements of production technologies have led to mass customisation (MC) combining high automation with high product variety. Furthermore, today's manufacturing landscape is increasingly shaped by regionalisation and globalisation leading to highly complex systems [1].

At the same time, the digital age, making this development possible in the first place, offers new opportunities for producers to utilise data and address user demands. Furthermore, the trend for individualisation has been growing in society for the last decades. Users now desire individual and personalised products to satisfy their needs. Driven by individualisation as a trend and enabled by increasing digitalisation, mass customisation and mass personalisation (MP) are the next steps where user demands are addressed directly and the user can even be integrated into the production process, increasingly becoming a "prosumer" $[2,3]$. 
The challenges arising with this paradigm shift are widely discussed in literature and mainly referred to as mass customisation MC [3-5] (see also section 3). The main dimensions of $\mathrm{MC}$ according to Boër et al. [3] are the integration of the customer by co-design and the integration of the individual needs that are reflected in a stable solution space and are available at an adequate price. An intrinsic value of every modern production process should be the inclusion of sustainability aspects, and thus should be part of MC/MP as well [3]. In this paper we distinguish between MC and MP based on the way of user integration. While $M C$ actively integrates the user into the development and selection procedures, MP extends the user comfort by giving recommendations based on user profiles or behavioural data and thus overcomes the agony of choice. The user can still play an active part in the process, but also become more passive by receiving recommendations based on personal preferences. While MP is not fully utilised in this paper, the term is used to demonstrate the ambition. When referring to the state of the art we use the term MC, while we refer to the general concept as MC/MP and to passive user integration as MP.

The overarching research question to which this work contributes is how MP can be utilised to improve sustainability. In order to quantify environmental impacts and thus show the relevance of assessing them, Life Cycle Assessment (LCA) is used to assess potential environmental impacts and potential reduction measures in two example scenarios. To do so, this paper shortly introduces the methodology of LCA according to ISO 14040/44 [6, 7]. Furthermore, a short overview of the current state of art and research in the area of MC/MP regarding sustainability is given based on existing literature and quantified by two example scenarios using LCA. Finally, further research needs and directions for the integration of LCA in the field of MC/MP are outlined.

\section{LIFE CYCLE ASSESSMENT METHODOLOGY}

LCA is an established and widespread methodology for evaluating the environmental impacts of a product system (a physical product or a service). The methodology of attributional LCA is internationally standardised in ISO 14040 and 14044 [6, 7] and is directly used in product development, but also in planning, policy-making and marketing. The method comprises the following four phases, which are described briefly below in their main objectives $[6,7]$ :

- Goal and scope definition: The goal of the study is defined and according to the goal the functional unit and system boundaries are set. Data requirements are identified and potential limitations are assessed.

- Inventory analysis: The identified data is collected and processed according to the goal and scope of the study.

- Impact assessment: The impact categories (e.g. Global Warming Potential) are selected including the appropriate characterisation models. Afterwards, the results of the inventory analysis are classified and characterised.

- Interpretation: The results are interpreted and prepared for the target audience.

The methodology of LCA is highly iterative and very flexible during its implementation. The complete framework including all phases is shown in Figure 1. Another important feature of an LCA is the life cycle perspective including all stages from resource extraction to disposal into the assessment, thus no unnoticed burden shifting is possible within the system boundaries.

Attributional LCA traditionally comes from a static and retrospective view on the product life cycle, yet, due to its flexibility and iterative character it is capable of adapting to the requirements of the agile environment of MC/MP. Further information about LCA can be found in [8] and [9].

As LCA only assesses environmental sustainability, it needs to be accompanied by other methods (cf. section 3 ). Due to the robustness and the maturity of the method, this study focusses on LCA, but further options are discussed in section 3.

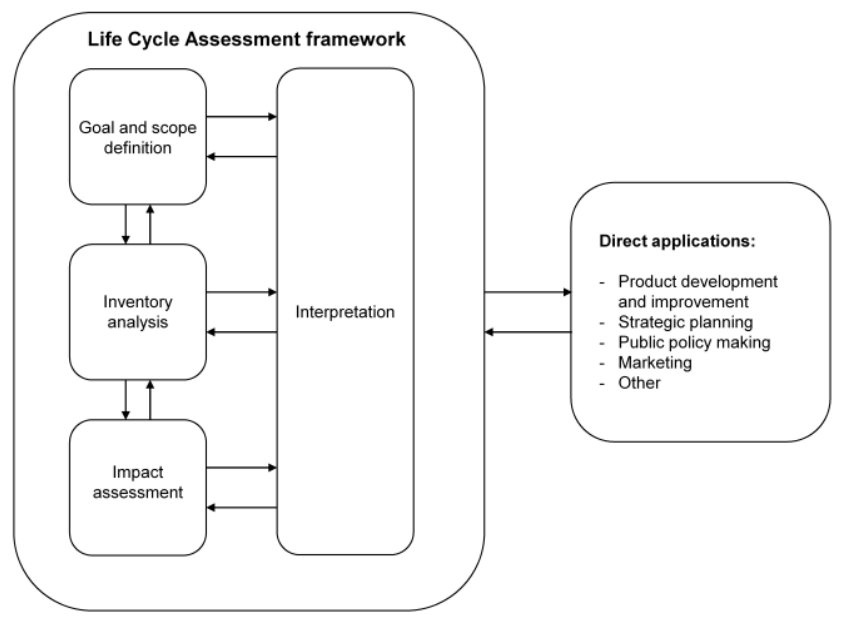

Figure 1 . Stages of the LCA methodology framework $[6,7]$

\section{SUSTAINABLE MASS CUSTOMISATION AND MASS PERSONALISATION}

MC/MP is a concept enabling the user to influence the environmental impacts of a product or service significantly, whereas conventionally this was mainly the case on the producer side. Due to this shift in power, it will be harder to locate and assess the environmental impacts. Thus, the risks and potentials of MC/MP can only be understood within its socioeconomic context, which needs to be examined regarding sustainability. The MC/MP trend is strongly influenced by different stakeholders, including politics, industry, academia and the user as the key stakeholder. MC/MP in its full extend creates a direct link between user and producer by collecting and transmitting data within the use phase. The use phase mostly plays an important role in the product life cycle, especially from an LCA perspective on the environmental impacts. Effects of the information from the use phase can create secondary effects on personalisation (e.g. 
changes in the product development phase). All these interrelations can have positive or negative impacts on the sustainability of a product.

These effects of MC and MP on sustainability have been a research topic in the last decade. The general field of research is called "Green Customization" [10] and mostly focusses on qualitative descriptions of different sustainability aspects. While most older studies address one aspect of MC and mainly focus on economic sustainability, recent studies increasingly address environmental sustainability in the context of MC/MP [11, 12]. For example, Hora et al. [13] provide a generic framework proposal with several business model patterns for sustainable MC. Trentin et al. [14] empirically investigate how MC and green management are interconnected and conclude that synergies exist between the two paradigms. Fornasiero et al. [15] integrate LCA into the supply chain management of customised products to evaluate the sustainability of different options. Pourabdollahian et al. [12] focus on identifying impact factors of $\mathrm{MC}$ on environmental sustainability using a product life cycle approach, propose a research agenda and emphasise the need for quantitative studies in this context.

In "Mass Customization and Sustainability" Boër et al. [3] propose a framework, and thus combine and formalise all relevant sustainability aspects, for the quantitative sustainability assessment of $\mathrm{MC}$ addressing economic, social and environmental aspects. LCA is proposed as the methodology of choice for the environmental aspects. An example scenario is described focussing on the Carbon Footprint. Brunø et al. [16] call for an assessment of the whole life cycle within MC and thus promote the LCA perspective as well without explicitly stating the need for the quantification of the impacts.

Yet it remains difficult to integrate sustainability aspects into MC/MP, as shown by Hankammer et al. [17] with only a minor share of configurators including these aspects at all. This is also reflected in the meta-study conducted by Gembarski et al. [18] finding that especially environmental aspects are vastly underrepresented in MC business models.

To cater for this dissonance in importance and penetration of sustainability assessment in MC, Medini et al. [19] propose an adjusted approach of the framework by Boer et al. based on specific needs of the stakeholder to minimise the efforts needed to undertake the assessment. Hänsch et al. [20] propose another method along the lines of simplification. Their SMC Excel Sustainability Approach explicitly only considers relevant deltas that occur with $\mathrm{MC}$ and thus save time. The approach can be seen as a streamlined LCA.

While MC relies mainly on the users' self-discipline and technological advancements for the improvement of sustainability, MP, according to the authors' understanding, can give support to the user to make preferable choices. This support includes purchase recommendations or use recommendations based on the users' profiles or behaviour. An example of choice navigation to foster sustainability is given by Badurdeen and Liyanage [21] and the general concept to foster sustainability by choice navigation is described. Osorio et al. [22] introduce the methodology of "Design for Sustainable Mass-Customization" and propose a guideline for the development of customised products. Betten et al. [23] describe and exemplarily apply the concept of using LCA to support product developers with the design of a new car component based on information about the use phase behaviour of potential users. The approach is similar to the one described by Hänsch et al. [20] as it also assesses changes in the product life cycle instead of absolute values.

All the described methods, concepts and technologies can be applied to MC/MP to improve different aspects. The aspects can be divided into the following objects based on Hankammer et al. [4]:

- Reduction of obsolete overproduction

- Extending the meaningful lifespan of products

- Sufficient consumption

- Resilient and self-sufficient local economies

- Collective and democratized downscaling

In the following two examples scenarios are explained and calculated to quantify the impacts on the different objectives and show the relevance of LCA as a tool for sustainability assessment.

\section{APPLICATION OF LCA IN THE CONTEXT OF MASS PERSONALISATION}

Actions are taken globally to reduce $\mathrm{CO}_{2}$-emissions and other pollutants. In the EU, one area of focus is the transport sector, as it is the leading source of air pollution in cities and contributes to around $25 \%$ of greenhouse gas emissions in Europe [24]. Measures to reduce these emissions include a higher transport efficiency as well as low-emission and locally emissionfree vehicles [24].

The focus of the following examples is put on the influence of (mass) personalisation in the (road) transport sector. Two illustrative example scenarios from this field were selected for this initial investigation. These example scenarios are of theoretical nature and purposely kept simple. They are meant to point out some of the relevant risks and potentials of MP in the context of environmental sustainability. In order to do so, the examples are underlined with quantitative LCA results to develop an understanding for the possible effects and interrelations. In accordance with the importance assessment of indicators in Boër et al. [3] the Carbon Footprint or Global Warming Potential is assessed being considered the most important and most scientifically sound indicator for environmental sustainability.

The first example on the return logistics of consumer products and the associated environmental burdens assesses a classic MC topic, with the main levers for sustainability being the reduction of overproduction and the extension of meaningful lifespan [4] by minimising secondary effects from logistics.

The second example evaluates an approach to select passenger cars according to the driving behaviour of the respective user taking into account the environmental impacts associated with each option. As 
in full application extensive information on user behaviour would be necessary the authors regard this example as a case of MP. The example mainly addresses the dimension of sufficient consumption [4].

\subsection{Example scenario 1: Logistics of personalised consumer products}

Consumer products, such as shoes or clothing, are considered in this example scenario. These products are increasingly ordered online through e-commerce platforms and sent in packages to the end user. The return policies usually allow returning the products within a given timeframe without additional costs. The return rate is especially high for clothing items and shoes with values of up to $50 \%[25,26]$. Due to the high return rate and the product variety offered by online retailers such as Amazon or Zalando, the return logistics are often costly and complex. For personalised products the return rate very likely decreases significantly, because users are more inclined to keep an item that is personalised to their individual wishes and sizing problems are less likely. A return rate of zero (assuming a functional product) is also viable within MP. At the moment the return policies of many companies offering customised products is strict and only allows a return if the product is defective [27]. Therefore, the amount of returns under MP is likely to be significantly reduced. The following examples show the potential of this effect for saving greenhouse gas (GHG) emissions.

According to [26], 250 million packages are returned annually in Germany, generating $123,667 \mathrm{t}$ of $\mathrm{CO}_{2}-$ emissions through transport alone. This number does not include further operations caused by the returned items.

Another example can be found in the annual report 2017 of one of the big European online retailers, which states that the corporate carbon footprint equals $2.54 \mathrm{~kg}$ $\mathrm{CO}_{2}$-equivalent $\left(\mathrm{CO}_{2}\right.$-eq.) per order and that $55 \%$ of these GHG emissions can be traced back to outbound logistics including returns [28]. It is not stated how high the return rate is or which specific operations of the return logistics are taken into account. However, it is assumed that the return rate is around $50 \%$ [29, 30].

Assuming that a returned order causes twice the amount of emissions due to logistical effort (delivery and return) compared to one that is retained by the user (only delivery), a GHG saving potential can be calculated for this case. 90.5 million orders were handled by the examined online retailer in 2017 in Europe resulting in approximately 126,429 t CO$_{2}$-eq. ${ }^{1}$ caused by outbound logistics operations. These emissions could be reduced significantly if the return rate is minimised. The following theoretical scenarios are meant to show this potential.

Depending on the return rate, different shares of the total GHG emissions can be traced back to returned and retained orders, respectively. These ratios are shown in Figure 2. The striped bars indicate the

\footnotetext{
${ }^{1} 55 \%$ of the carbon footprint of 90.5 million orders $(2.54 \mathrm{~kg}$ $\mathrm{CO}_{2}$-eq. per order) [28]
}

emissions from returned orders and therefore the potential to reduce GHG emissions through lower return rates associated with MP. A high reduction potential is found for the current high return rate of $50 \%$.

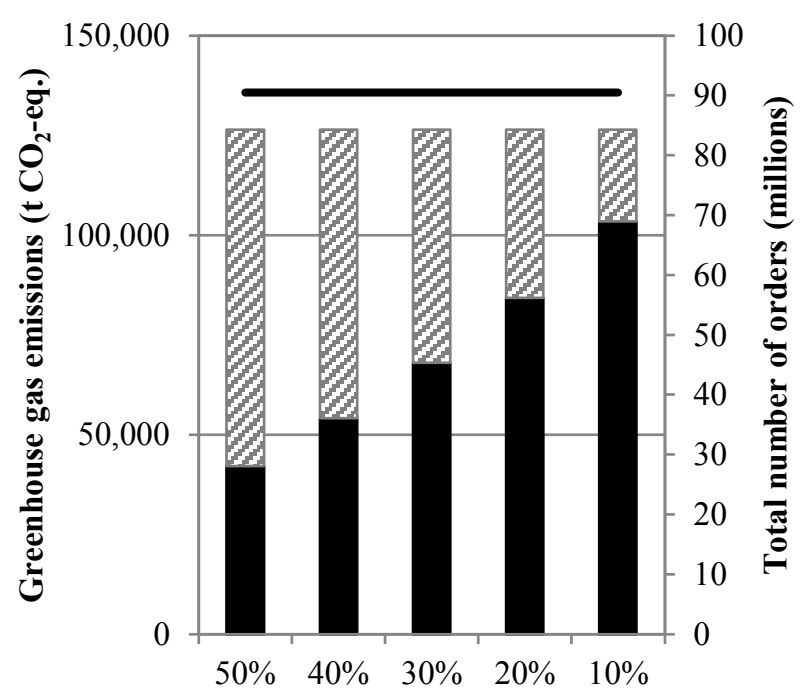

Return rate

007 Emissions from returned orders

Emissions from retained orders

Total number of orders

Figure 2. Share of emissions caused by outbound logistics of returned and retained orders for different return rates (and constant 90.5 million orders in total)

Considering that the number of retained orders represents the actual need of the customers, it is assumed that this number stays constant under MP. For this case, the emissions for lower return rates at constant retained orders can be calculated. Assuming that the current return rate is $50 \%$ for 90.5 million total orders, the actual demand would be 45.25 million orders. Based on this constant demand, the emissions for different return rates and the resulting total number of orders are shown in Figure 3. With a decreasing return rate the $\mathrm{GHG}$ emissions of the returns decrease from approximately $85,000 \mathrm{t} \mathrm{CO}_{2}$-eq. (50\% return rate) to approximately 10,000 t CO$_{2}$-eq. (10\% return rate). At the same time the total number of orders decreases from 90.5 million to roughly 50 million.

The results clearly show the high potential that lies in the reduction of the return rate of consumer products through personalisation. Comparing the "status quo" results (50\% return rate) of this example with the results for a return rate of $10 \%$ reveals that, while the carbon footprint of each order can be reduced by approximately $25 \%$, the GHG emissions of the total number of orders are reduced by almost $60 \%$. This effect is due to the lower number of total orders. However, these results only include the emissions from outbound logistics. Additional steps resulting in even higher emissions of returned items, such as washing and repackaging, are not taken into account here. Furthermore, a lower number of total orders due to a lower return rate would also influence other areas of a 
corporation. It can be assumed that these effects would lead to a higher efficiency in at least some of these areas as well, therefore likely further reducing the overall corporate carbon footprint.

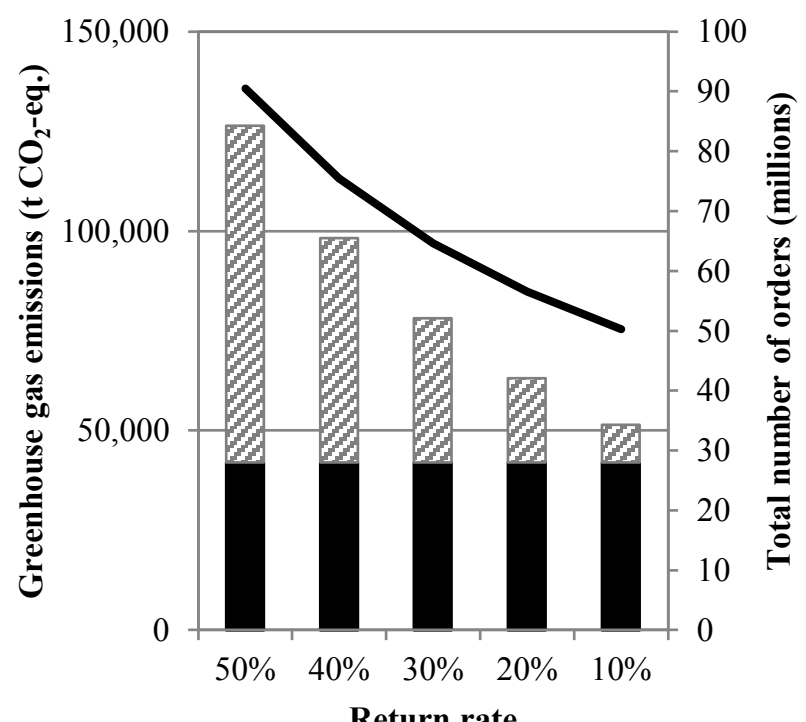

200 Emissions from returned orders

Emissions from retained orders

Total number of orders

Figure 3. Share of emissions caused by outbound logistics of returned and retained orders for different return rates (and constant 45.25 million retained orders)

\subsection{Example scenario 2: Vehicle selection based on personal driving behaviour}

One alternative for passenger transport to conventional fossil fuelled vehicles are battery electric vehicles (BEVs). These vehicles offer the advantage of being locally emission-free, thus improving urban air quality. How much and under which circumstances these vehicles can contribute to a reduction of $\mathrm{GHG}$ emissions depends mainly on the electricity used for charging. This has been verified by various studies, such as [31] and [32].

Personalisation could play a key role in enabling the full potential of electric vehicles. Besides customisation or personalisation regarding design options, the battery system of the BEV could be scaled to the actual demand of its designated user, potentially saving resources required to produce a standardised (possibly oversized) system. Furthermore, by analysing the user behaviour, ideal vehicles or vehicle combinations regarding the user needs and the environmental performance could be selected. Thus, this example scenario aims at personalising the vehicle selection to the user behaviour from an environmental point of view. Therefore, the following example scenario is a more abstract view on MP, as it examines how optimisation regarding the use phase and predicted usage patterns can minimise environmental impacts of personal transport.
First, the statistical driving behaviour of car owners in Germany is investigated in order to classify these users into groups with different demands. Subsequently, an LCA is implemented for different vehicle options and driving profiles. Finally, the most environmentally friendly solution satisfying the needs of each user group is found and evaluated.

\subsubsection{Identification of current user behaviour}

The average German car owner has an annual mileage of $15.320 \mathrm{~km}$ corresponding to a daily mileage of $42 \mathrm{~km}$ [33]. Table 1 shows the distribution of the annual mileage over the different mileage classes in Germany for the year 2016 [33] and the classification into three user types defined for this example. Table 2 shows the average annual and daily mileages (based on 33), and the share of urban, rural and highway driving (based on 34) for the three classified user types.

Table 1. Classification of users based on the annual mileage of German car owners [33]

\begin{tabular}{|l|c|c|c|}
\hline $\begin{array}{l}\text { Annual } \\
\text { mileage (km) }\end{array}$ & $\begin{array}{c}\text { Daily } \\
\text { average } \\
\text { (km) }\end{array}$ & $\begin{array}{c}\text { Share } \\
\text { (\%) }\end{array}$ & $\begin{array}{c}\text { User } \\
\text { classification }\end{array}$ \\
\hline$<5,000$ & $<13.7$ & 5 & \multirow{2}{*}{ A $(24 \%)$} \\
\hline $5,000-9,999$ & 20.5 & 19 & \\
\hline $10,000-12,999$ & 31.5 & 27 & \multirow{2}{*}{ B $(49 \%)$} \\
\hline $13,000-15,999$ & 39.7 & 18 & \\
\hline $16,000-19,999$ & 49.3 & 4 & \\
\cline { 1 - 3 } $20,000-24,999$ & 61.6 & 13 & \multirow{2}{*}{ C $(27 \%)$} \\
\hline $25,000-29,999$ & 75.3 & 5 & \multirow{2}{*}{} \\
\hline$>30,000$ & $>82.2$ & 9 & \\
\hline
\end{tabular}

The three user types are characterised as follows:

- Type A: This user group is characterised by short routes with an average daily mileage of 19.1 $\mathrm{km}$. It is assumed that most of the travelled routes are urban and that longer distances are avoided or preferably not driven by car, but by other means of transport.

- Type B: This is the most common user type in Germany. It is assumed that this person has a high share of urban driving, but also travels on routes with higher distances occasionally.

- Type C: The longest distances are travelled by users of this group. It is assumed that a high share of routes is rural and highway driving.

Table 2. Average mileage for each user type (based on 33) and share of urban, rural and highway traffic (own assumptions based on 34)

\begin{tabular}{|c|c|c|c|c|c|}
\hline \multirow{2}{*}{$\begin{array}{c}\text { User } \\
\text { type }\end{array}$} & \multicolumn{2}{|c|}{ Mileage (km) } & \multicolumn{3}{c|}{ Share (\%) } \\
\cline { 2 - 6 } & $\mathbf{1 / a}$ & $\mathbf{1 / d}$ & urban & rural & highway \\
\hline A & 7,000 & 19.1 & 80 & 15 & 5 \\
\hline B & 13,100 & 36.0 & 50 & 30 & 20 \\
\hline C & 25,900 & 71.0 & 25 & 35 & 40 \\
\hline
\end{tabular}

\subsubsection{Selection of vehicles}

Six generic vehicles are available: two conventional vehicles (petrol and diesel powered) and one BEV in two sizes each (mini and compact class). The main vehicle parameters, such as weight, average 
consumption (for each user group) and battery capacity for the BEVs are summarised in Table 3.

Table 3. Vehicle parameters (adapted from 34)

\begin{tabular}{|l|r|r|r|r|r|}
\hline \multirow{2}{*}{ Vehicle } & \multirow{2}{*}{$\begin{array}{l}\text { Weight } \\
\text { (kg) }\end{array}$} & \multicolumn{5}{|c|}{ Average consumption } \\
\cline { 3 - 5 } & & A & \multicolumn{1}{|c|}{ B } & C & \multirow{2}{*}{ Unit } \\
\hline Mini class \\
\hline $\begin{array}{l}\text { BEV } \\
\text { (14 kWh) }\end{array}$ & 960 & 12.8 & 15.4 & 18.2 & $\begin{array}{c}\mathrm{kWh} / \\
100 \mathrm{~km}\end{array}$ \\
\hline $\begin{array}{l}\text { CV } \\
\text { (petrol) }\end{array}$ & 850 & 5.7 & 5.6 & 5.7 & $1 / 100 \mathrm{~km}$ \\
\hline $\begin{array}{l}\text { CV } \\
\text { (diesel) }\end{array}$ & 870 & 4.2 & 3.9 & 3.7 & $1 / 100 \mathrm{~km}$ \\
\hline
\end{tabular}

\section{Compact class}

\begin{tabular}{l|r|c|c|c|c|}
\hline $\begin{array}{l}\text { BEV } \\
(40 \mathrm{kWh})\end{array}$ & 1,540 & 16.2 & 18.5 & 21.2 & $\begin{array}{c}\mathrm{kWh} / \\
100 \mathrm{~km}\end{array}$ \\
\hline $\begin{array}{l}\text { CV } \\
\text { (petrol) }\end{array}$ & 1,307 & 6.7 & 6.6 & 6.7 & $\mathrm{l} / 100 \mathrm{~km}$ \\
\hline $\begin{array}{l}\text { CV } \\
\text { (diesel) }\end{array}$ & 1,370 & 5.2 & 4.9 & 4.8 & $\mathrm{l} / 100 \mathrm{~km}$ \\
\hline $\begin{array}{l}\text { BEV battery electric vehicle } \\
\text { CV } \\
\text { conventional vehicle }\end{array}$
\end{tabular}

\subsubsection{Implementation into LCA}

All generic vehicles are modelled in the "GaBi ts" software and database system [35]. The system boundary is illustrated in Figure 4 . The following points are taken into account:

- Production of vehicles and fuels including the respective background systems

- Combustion of conventional fuels

- Electricity demand of BEVs (the German grid mix and electricity from wind power are evaluated)

- Recycling and disposal efforts without recycling credits

The functional unit is $1 \mathrm{~km}$ of passenger transport and a lifetime of 12 years for the vehicles is assumed.

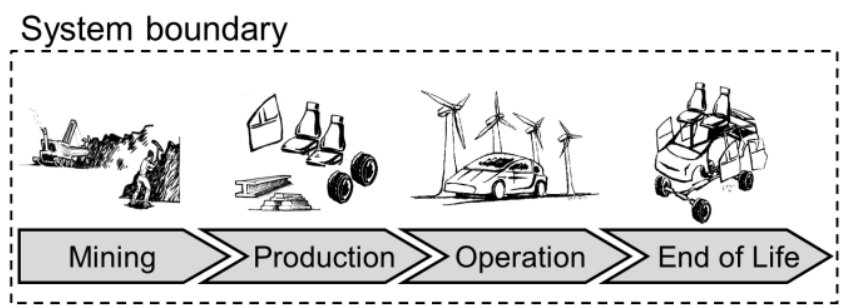

Figure 4. System boundary (illustration by 36 )

Due to the screening character of this study, the impact assessment is limited to the Global Warming Potential (GWP $\left.{ }_{100}\right)$ according to the CML methodology [9]. Relevant emissions are converted to $\mathrm{CO}_{2}$-equivalents ( $\mathrm{CO}_{2}$-eq.) according to characterisation factors [37] and added up. Table 4 provides an overview over the $\mathrm{GWP}_{100}$ of the analysed fuels (including electricity).
Table 4. GWP 100 of fuels used in the scenarios [35]

\begin{tabular}{|c|c|c|}
\hline Fuel & GWP $_{100}$ & Unit and Comment \\
\hline Petrol & 2780 & \multirow{2}{*}{$\begin{array}{l}\mathrm{g} \mathrm{CO}_{2} \text {-eq./litre } \\
\text { production and } \\
\text { combustion } \\
\end{array}$} \\
\hline Diesel & 2918 & \\
\hline $\begin{array}{l}\text { Electricity } \\
\text { (GER grid mix) }\end{array}$ & 543 & $\begin{array}{l}\mathrm{g} \mathrm{CO}_{2} \text {-eq./kWh } \\
\text { average of dynamic } \\
\text { grid mix (12 years) }\end{array}$ \\
\hline $\begin{array}{l}\text { Electricity } \\
\text { (from wind } \\
\text { power) }\end{array}$ & 9 & $\begin{array}{l}\mathrm{g} \mathrm{CO}_{2}-\mathrm{eq} . / \mathrm{kWh} \\
\text { wind power in } \\
\text { Germany }\end{array}$ \\
\hline $\begin{array}{l}\mathrm{CO}_{2-e q} \\
\text { GER } \\
\text { GWP }_{100}\end{array}$ & ing pote & ntial (100 years) \\
\hline
\end{tabular}

\subsubsection{LCA results}

The results of user group $A$ and $C$ are presented first. User group $B$ is analysed in further depth in the end.

\section{Results for user group $A$}

The results for the GWP 100 for user group $A$ are shown in Figure 5. It is assumed that mini-class vehicles are preferred by this user group and thus only the results for the evaluated mini-class vehicles are shown in the figure for a better overview. The results of the compactclass vehicles are higher compared to the respective mini-class vehicles due to higher impacts from production and a higher consumption of the compactclass vehicles. Furthermore, the range of the mini BEVs (approximately $90 \mathrm{~km}$ based on the average consumption of user group A and considering a maximum state of discharge of the battery of $80 \%)^{2}$ is considered sufficient for this user group due to the average daily mileage of $19.1 \mathrm{~km}$.

The petrol vehicle shows the highest results at the end of a 12 year lifetime with an annual mileage of $7,000 \mathrm{~km}$. The second highest lifetime results can be observed for the diesel vehicle. The BEVs start with a higher burden from the production mainly due to the battery system, but have overall lower impacts at the end of their lifetime compared to the conventional vehicles. Depending on the technology used to generate the electricity, the impacts are between $11 \%$ lower (German grid mix) and $52 \%$ lower (wind power). The break-even point with the diesel vehicle occurs at approximately $56,000 \mathrm{~km}$ if the BEV is charged from the German grid or at approximately $23,000 \mathrm{~km}$ if electricity from wind power is provided. Both break-even points are likely reached by the typical user of group A within the lifetime of the vehicle.

\section{Results for user group C}

The results for the GWP 100 for user group $C$ can be found in Figure 6. It is assumed that this user group prefers compact-class vehicles over mini-class vehicles. Therefore, only the results for the evaluated compactclass vehicles are shown. Furthermore, the range of a mini BEV (approximately $60 \mathrm{~km}$ based on the average

\footnotetext{
${ }^{2}$ All range calculations consider a maximum state of discharge of the battery of $80 \%$.
} 
consumption of user group C) would not be sufficient to satisfy the needs of this group.

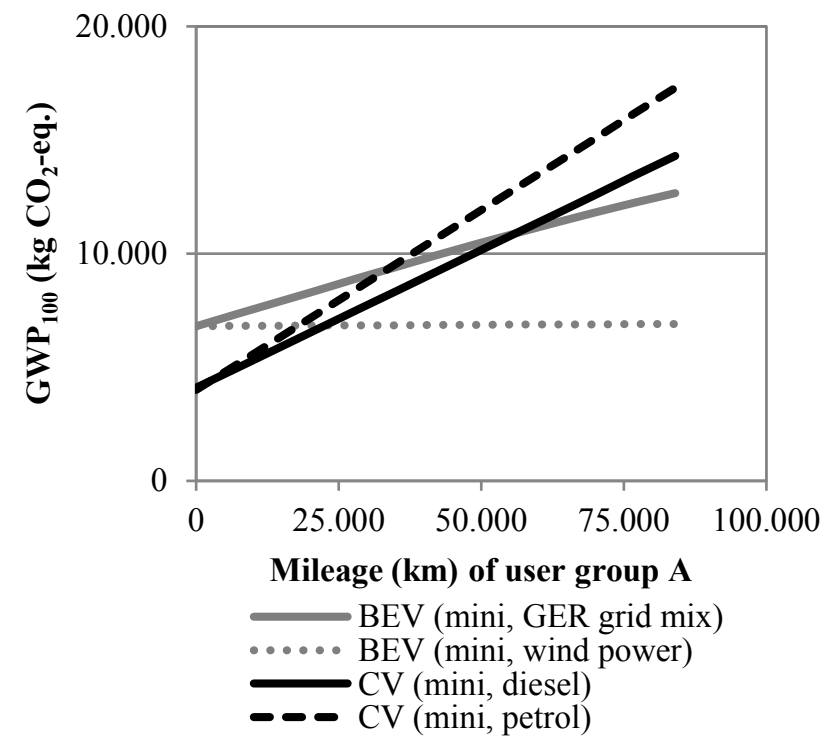

Figure 5. Global Warming Potential for user group A with different mini-class vehicles

The results show that the compact petrol vehicle has the highest GWP100 results after a lifetime of 12 years. The BEV has lower results than the petrol vehicle and slightly lower results compared to the diesel vehicle if the electricity is supplied by the German grid mix. However, in this case the break-even point occurs at approximately $300,000 \mathrm{~km}$ just before the end of life. Therefore, it cannot be recommended to use the BEV instead of the diesel vehicle due to the late break-even point that might not be reached in some cases. Furthermore, the range of the evaluated compact BEV is approximately $150 \mathrm{~km}$ at average consumption. This range is theoretically sufficient for the average daily mileage of $71 \mathrm{~km}$ but could be seen as challenging for longer routes that this user will likely drive regularly.

In the case that the BEV could be supplied with electricity from renewable sources and if the range is not seen as challenging, it is worth considering this option instead of the diesel vehicle. The wind powered compact BEV offers GHG emission reductions of over $70 \%$ compared to the compact diesel vehicle with the break-even point at approximately $52,000 \mathrm{~km}$.

\section{Results for user group B}

User group $B$ is the largest and most diverse of the three groups (see Table 1). Due to the high uncertainties for this group as a whole, more specific scenarios are required.

Therefore, a concept is assessed, where users own a mini BEV for urban driving and are supplied with a diesel vehicle for routes with longer distances. In this case the latter is part of a car sharing concept, which is not discussed in further depth for this study. It is assumed that the diesel vehicle can be supplied when needed and that user acceptance is high. Table 5 summarises the parameters for the evaluated scenarios for user group B.

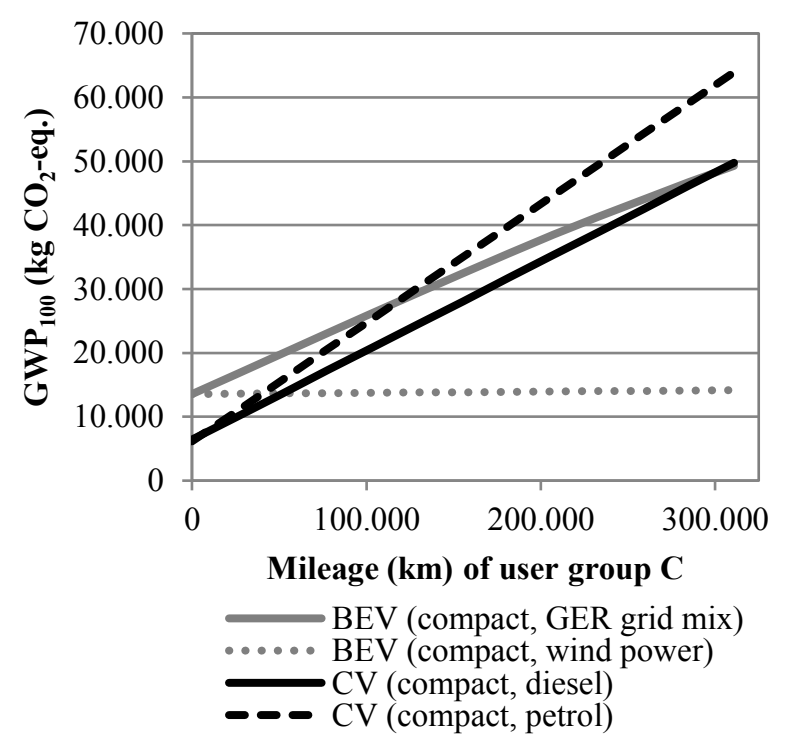

Figure 6. Global Warming Potential for user group $C$ with different compact-class vehicles

Table 5. Scenarios for user group B

\begin{tabular}{|c|c|c|c|c|c|}
\hline $\begin{array}{l}\text { Sce- } \\
\text { nario }\end{array}$ & Vehicle(s) & $\begin{array}{c}\text { Con- } \\
\text { sumption }\end{array}$ & $\begin{array}{c}\text { Mileage } \\
\text { BEV } \\
\left(\mathrm{kmel}^{2} / \mathrm{a}\right)\end{array}$ & $\begin{array}{c}\text { Mileage } \\
\text { CV } \\
\left(\mathrm{km}_{\mathrm{cv} / \mathrm{a}}\right)\end{array}$ & SF \\
\hline BA & mini BEV & average $\mathrm{B}$ & 13,100 & 0 & - \\
\hline B1 & \multirow{5}{*}{$\begin{array}{l}\text { combina- } \\
\text { tion of mini } \\
\text { BEV and } \\
\text { compact } \\
\text { diesel CV }\end{array}$} & \multirow{2}{*}{$\begin{array}{l}\text { BEV: } \\
\text { urban }\end{array}$} & 10,000 & 3,100 & 0.20 \\
\hline B2 & & & 7,500 & 5,600 & 0.25 \\
\hline B3 & & \multirow{3}{*}{$\begin{array}{l}\text { CV: } \\
\text { average B }\end{array}$} & 6,550 & 6,550 & 0.33 \\
\hline B4 & & & 5,000 & 8,100 & 0.50 \\
\hline B5 & & & 2,500 & 10,600 & 1 \\
\hline$B C$ & $\begin{array}{l}\text { compact } \\
\text { diesel CV }\end{array}$ & average B & 0 & 13,100 & - \\
\hline BEV & \multicolumn{5}{|c|}{ Battery electric vehicle } \\
\hline CV & \multicolumn{5}{|c|}{ Conventional vehicle } \\
\hline $\mathrm{kmel} / \mathrm{a}$ & \multirow{2}{*}{\multicolumn{5}{|c|}{$\begin{array}{l}\mathrm{km} \text { driven electrically (BEV) per year } \\
\mathrm{km} \text { driven diesel powered (CV) per vear }\end{array}$}} \\
\hline $\mathrm{kmcv/a}$ & \multirow{2}{*}{\multicolumn{5}{|c|}{$\begin{array}{l}\mathrm{km} \text { driven diesel powered (CV) per year } \\
\text { Sharing factor }\end{array}$}} \\
\hline SF & & & & & \\
\hline
\end{tabular}

The German grid mix is taken into account for the electricity supply and the total mileage is $13,100 \mathrm{~km}$ per year over a lifetime of 12 years in all scenarios. The sharing factor (SF) applies to scenarios B1-B5 and indicates the share of the burdens from the production of the shared diesel vehicle allocated to the user depending on the number of people sharing one vehicle. For example, while five people share the diesel vehicle in scenario B1 resulting in SF $=0.2(20 \%$ of the burdens from the production are allocated to the user), the diesel vehicle is exclusive to the user in scenario B5 (SF = 1).

Scenario BA relates to users of group $B$ that are close to user group $A$ in their behaviour. A mini BEV with the average consumption and mileage of group $B$ is taken into account, as it is likely that the range of the mini BEV would be sufficient for these users. Similarly, scenario $B C$ relates to users of group B that are close to users of group $\mathrm{C}$ and would benefit from the range of a conventional vehicle.

The results for user group B are displayed in Figure 7. The effect of the sharing concept depends on two independent parameters: the ratio between electric and diesel powered driving and the sharing factor regarding 
the diesel vehicle. Generally, the overall greenhouse gas emissions decrease if the electrically driven mileage increases. This is due to the low consumption of the BEV under urban conditions. For example, in scenario B4 $5,000 \mathrm{~km} / \mathrm{a}$ are driven with a mini BEV (which is less than the annual mileage of user group A) and the diesel compact vehicle is shared with only one other person $(S F=0,5)$ leading to lower lifetime emissions compared to scenario $\mathrm{BC}$, where only the diesel vehicle is used. Scenario B5, on the other hand, shows that if the mileage of the BEV is relatively low $(2,500 \mathrm{~km}$ el. $/ \mathrm{a}$ in this case $)$ and the diesel $\mathrm{CV}$ is not shared, the combination is not sufficient to achieve lower emissions. However, if the sharing factor is lower (i.e. more people sharing the vehicle), the results decrease significantly. For the mileage distribution of scenario B5 (2,500 kmel./a and $\left.10,600 \mathrm{~km}_{\mathrm{cv}} / \mathrm{a}\right)$, $\mathrm{SF}=0,25$ is required to yield lower lifetime emissions compared to scenario BC.

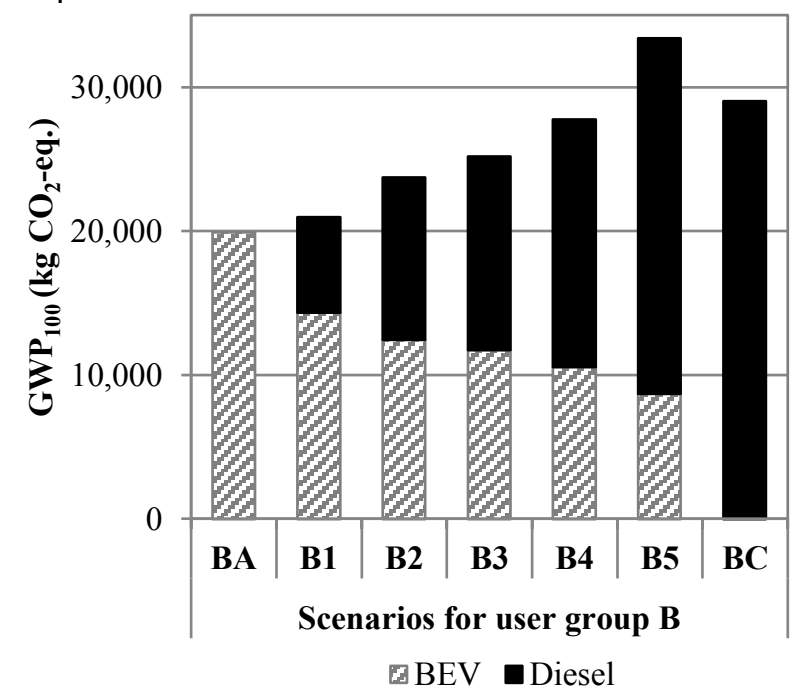

Figure 7. Global Warming Potential for different scenarios of user group $B$

This example demonstrates that, based on the individual users and their driving patterns, personalised vehicle or vehicle combination can be selected regarding the environmental performance. Depending on the user's values, this might be an important factor to include during the personalisation process.

\section{CONCLUSION}

The concept of MC/MP evolves with and centres on the individual user. Thus, the way we produce and use products and services will change significantly. This development bears potentials and also risks on different levels including impacts on the environment.

\subsection{Discussion}

This paper focusses on two simple example scenarios about possible developments within MC/MP to demonstrate these potentials and risks. The first example scenario assesses potential effects of MC/MP on the return logistics in the online retail business. A simple back of the envelope calculation examines the environmental impacts (i.e. GHG emissions) in the context of avoided order returns and shows significant mitigation potentials for lower return rates. This could be achieved through tools and techniques of MP (e.g. virtual dressing room or sizing based on user data). Furthermore, this quantitative example underlines the qualitative findings in the literature regarding return logistics, such as mentioned by [12], and therefore contributes to closing the research gap in this regard.

The second example scenario examines how individual transport choices influence the environmental impacts. In the example scenario, users have the choice between conventional and battery electric vehicles (with preselected vehicle options). Based on the behavioural patterns of different user groups, the GWP results can differ significantly, according to their vehicle selection. Within MP, users could be supported (e.g. by software) in their choices based on their personal preferences and behaviour.

The present example only considered the passenger vehicle choice. However, in order to unlock higher emission reduction potentials, other transport options should be considered as well. In a study by Anagnostopoulou et al. [38] users are supported in their transport choices for urban routes by a mobile application for route planning. Different route options and transport modes (car, bike, public transport, walking) are suggested based on the users' personality and "mobility type". The overall aim is to persuade users to choose more environmentally friendly options by informing them about the $\mathrm{CO}_{2}$-profile of their choices and by displaying persuasive messages, again based on a personalisation algorithm. The authors report successful persuasion, but reveal a bias of their study in the fact that mostly already eco-conscious users took part in it. Assuming that not every user prefers a more environmentally friendly option in any circumstances and at all costs, information about the environmental consciousness and awareness of each individual user needs to be investigated in order to personalise successfully. In this context, Hankammer et al. [39] propose an optimisation model for a configurable product based on the customer's sustainability preferences in all three dimensions (economical, environmental, social). Similarly, the authors point out that the limitations of the proposed framework lie within the knowledge of the user regarding the applied sustainability concept, highlighting the necessity to empower the user by providing relevant information to enable informed decision making.

In the present study, both example scenarios demonstrate the significance of MC/MP for environmental sustainability. In the first example scenario the trend creates an indirect effect by avoiding unnecessary order returns and in the second example scenario the user choice could be assisted directly to mitigate environmental impacts. As can be seen in these two simple scenarios, decisions can become complex quite quickly. The complexity increases if a subject, such as sustainability, is the object of the decision-making process, as it is less tangible compared to conventional and common decisionsupport quantities, such as time or monetary value. 
MC/MP is a threat to sustainability, but also an opportunity. Effects and issues similar to the ones discussed in this paper will also arise in other fields and topics related to MC/MP. Thus, the trend needs to be moderated to ensure a favourable impact on sustainability. For this purpose in general, the users require tools to express and evaluate their own environmental consciousness, needs and values. In general MC/MP affects sustainability in two different ways:

- Effects created within society as a whole.

- Effects created by single users, by individual and informed decision making.

When evaluating sustainability both aspects need to be taken into consideration.

\subsection{Outlook and research needs}

The authors contribute the perspective of LCA practitioners to the field of MC/MP. In the future the used terms will need to converge with the terms used in the MC community, bridging the gap between the different core research areas.

Furthermore, sustainability cannot be reduced to impacts on climate change alone. Therefore, environmental assessments with a broader scope than screening need to include other environmental impact categories and dimensions, such as resource consumption and social aspects, as well.

As described above, MP will integrate the user into the product development process and various decisions in the use phase. However, the user needs to be addressed in a simple and comprehensible (possibly even personalised) way, so interfaces addressing the user's needs and enabling interaction between the user and producer will be required.

This study only focused on broad user groups or the whole customer group, yet, already demonstrated potentials to increase environmental sustainability. Looking at individual users could unlock even greater potential. Simultaneously, user data will become much more diverse (e.g. lot-size 1 or individualised use phase) and to deal with these data, techniques of data science (e.g. artificial intelligence or big data) and psychology (e.g. user and behavioural models) need to be embedded within the available and future tools for environmental assessment. As mentioned above, one established and robust tool for environmental assessment is LCA. In traditional LCA, often a standard use phase is assumed, but with MP a much stronger focus on the use phase will be needed, as significant differences between single users can be expected. This will require more agile approaches within the LCA methodology to address this development. As a consequence of the user being the key stakeholder in $\mathrm{MP}$, the acquisition and use of user data will be essential as an enabler. Legal and ethical issues around data security will be of interest for all involved parties and need to be ensured in every tool and process.

To address and understand the phenomena of environmentally sustainable MC/MP holistically all stakeholders need to be involved, including academia, politics, industry and of course the user. In order to achieve this, intensive exchange with politics is needed to ensure beneficial implementation of environmentally sustainable MC/MP needs into laws and regulations. Industry is needed for joint projects or strategic partnerships to ensure best connectivity of concepts developed with academia to current technologies and easy implementation.

\section{ACKNOWLEDGMENTS}

The authors would like to thank the Ministry of Science, Research and Arts and the Ministry of Economic Affairs, Labor and Housing Construction of the German state of Baden-Württemberg for the funding of this work within the High-Performance Center "Mass Personalization" in Stuttgart.

The High-Performance Center "Mass Personalization", is a cooperation of the four Fraunhofer institutes in Stuttgart, the University of Stuttgart and industry partners. The focus of the project lies on developing and improving key enabling technologies for Mass Personalization and on ensuring sustainable development in this context [40,41].

More information can also be found at www.masspersonalization.de.

\section{REFERENCES}

[1] Hu, S. J. (2013), "Evolving Paradigms of Manufacturing. From Mass Production to Mass Customization and Personalization", Procedia CIRP, Vol. 7, pp. 3-8.

[2] Bauernhansı, T. (2017), "Mass Personalization - der nächste Schritt", wt Werkstatttechnik online, Vol. 107, No. 3, p. 107.

[3] Boër, C. R., Pedrazzoli, P., Bettoni, A. and Sorlini, M. (2013), Mass Customization and Sustainability, Springer London, London, United Kingdom.

[4] Hankammer, S. and Kleer, R. (2018), "Degrowth and collaborative value creation. Reflections on concepts and technologies", Journal of Cleaner Production, Vol. 197, pp. 1711-1718.

[5] Hankammer, S., Nielsen, K., Piller, F. T., Schuh, G. and Wang, N. (2018), Customization 4.0, Springer International Publishing, Cham, Switzerland.

[6] Deutsches Institut für Normung (2006), DIN EN ISO 14040 : Environmental management - life cycle assessment - Principles and framework, Beuth Verlag, Berlin, Germany.

[7] Deutsches Institut für Normung (2006), DIN EN ISO 14044: Environmental management - life cycle assessment Requirements and guidelines, Beuth Verlag, Berlin, Germany.

[8] Finkbeiner, M. (2016), Special Types of Life Cycle Assessment. LCA Compendium - The Complete World of Life Cycle Assessment, Springer Netherlands, Dordrecht, The Netherlands.

[9] Guinée, J. B. and Lindeijer, E. (2002), Handbook on life cycle assessment. Operational guide to the ISO standards. Ecoefficiency in industry and science, Vol. 7, Kluwer, Dordrecht, The Netherlands.

[10] Chin, R. and Smithwick, D. (2009), "Environmental Impacts of Utilizing Mass Customization: Energy and Material Use of Mass Customization vs. Mass Production", in 2009 Proceedings 5th World Conference on Mass Customization \& Personalization MCPC2009, Helsinki, Finland.

[11] Fogliatto, F. S., da Silveira, G. J.C. and Borenstein, D. (2012), "The mass customization decade. An updated review of the literature", International Journal of Production Economics, Vol. 138, No. 1, pp. 14-25.

[12] Pourabdollahian, G., Steiner, F., Rasmussen, O. H. and Hankammer, S. (2014), "A Contribution toward a Research Agenda: Identifying Impact Factors of Mass Customization on 
Environmental Sustainability", International Journal of Industrial Engineering and Management, Vol. 5, No. 4, pp. 169-178.

[13] Hora, M., Hankammer, S., Canetta, L., Sel, S. K., Gomez, S. and Gahrens, S. (2016), "Designing Business Models for Sustainable Mass Customization: A Framework Proposal", International Journal of Industrial Engineering and Management, Vol. 7, No. 4, pp. $143-152$

[14] Trentin, A., Forza, C. and Perin, E. (2015), "Embeddedness and path dependence of organizational capabilities for mass customization and green management. A longitudinal case study in the machinery industry", International Journal of Production Economics, Vol. 169, pp. 253-276.

[15] Fornasiero, R., Brondi, C. and Collatina, D. (2017), "Proposing an integrated LCA-SCM model to evaluate the sustainability of customisation strategies", International Journal of Computer Integrated Manufacturing, Vol. 30, No. 7, pp. 768-781.

[16] Brunø, T. D., Nielsen, K., Taps, S. B. and Jørgensen, K. A (2013), "Sustainability Evaluation of Mass Customization", in Prahbu V. (Ed.), Advances in Production Management Systems. Sustainable Production and Service Supply Chains, 2013 Proceedings, Part I of IFIP WG 5. 7 International Conference, APMS 2013, State College, PA, USA, pp. 175-182.

[17] Hankammer, S., Hora, M., Canetta, L. and Sel, S. K. (2016), "User-Interface Design for Individualization Services to Enhance Sustainable Consumption and Production", Procedia CIRP, Vol. 47, pp. 448-453.

[18] Gembarski, P. C., Schoormann, T., Schreiber, D., Knackstedt, R. and Lachmayer, R. (2018), "Effects of Mass Customization on Sustainability: A Literature-Based Analysis" in Hankammer et al. (Eds.) Customization 4.0, Springer International Publishing, Cham, Switzerland, pp. 285-300.

[19] Medini, K., Da Cunha, C. and Bernard, A. (2014), "Tailoring performance evaluation to specific industrial contexts application to sustainable mass customisation enterprises", International Journal of Production Research, Vol. 53, No. 8, pp. 2439-2456.

[20] Hänsch, A., Hora, M., Fontana, A., Hankammer, S., Canetta, L. and Gomez, S. (2018), "A Preparatory Approach to Environmental Assessment for Sustainable Mass Customization", in Hankammer et al. (Eds.) Customization 4.0, Springer International Publishing, Cham, Switzerland, pp. 315-337.

[21] Badurdeen, F. and Liyanage, J. P. (2011), "Sustainable value co-creation through mass customisation. A framework", International Journal of Sustainable Manufacturing, Vol. 2, No. 2/3, pp. 180-203.

[22] Osorio, J., Romero, D., Betancur, M. and Molina, A. (2014), "Design for sustainable mass-customization. Design guidelines for sustainable mass-customized products", in 2014 Proceedings of the International ICE Conference on Engineering, Technology and Innovation (ICE), Bergamo, Italy, pp. 1-9.

[23] Betten, T., Bouslama, R., Wehner, D. and Uusitalo, V. (2019), "Unlocking sustainability potentials in product development through extended knowledge and predictions about the product use phase", in Binz $\mathrm{H}$. et al. (Eds.), Proceedings of the Stuttgarter Symposium für Produktentwicklung SSP 2019. Stuttgart, Germany, pp. 223-232.

[24] European Commission (2016), "Communication from the Commission to the European Parliament, the Council, the European Economic and Social Committee and the Committee of the Regions - A European Strategy for Low-Emission Mobility", 20.07.2016, Brussels, Belgium.

[25] Cullinane, S., Browne, M., Karlsson, E. and Wang, Y. (2017), "Improving Sustainability through Digitalisation in Reverse Logistics", in Jan, C. et al. (Eds.) Digitalization in maritime and sustainable logistics. City logistics, port logistics and sustainable supply chain management in the digital age, 2017 Proceedings of the Hamburg International Conference of Logistics (HICL)

[26] "Return to Sender. Grafik 175", Die Zeit, No. 43 (Oct. 2012), pp. 41.

[27] Liu, N., Choi, T.-M., Yuen, C.-W. M. and Ng, F. (2012), "Optimal Pricing, Modularity, and Return Policy Under Mass Customization", IEEE Transactions on Systems, Man, and Cybernetics-Part A: Systems and Humans, Vol. 42, No. 3, pp. 604-614.

[28] Zalando SE, "Annual Report 2017", available at: https://corporate.zalando.com/sites/default/files/mediadownload/zalando_se_annual_report_2017.pdf. (accessed: $28^{\text {th }}$ May 2019)
[29] Güntert, A. and Frommberg, L. (2016), "Warum sich Zalando über viele Rücksendungen freut", Handelszeitung, 2.11. 2016.

[30] Seidel, H. (2013), "Zalando kämpft um den ersten Platz bei Fashion", Welt, 9.7.2013 , available at: https://www.welt.de/wirtschaft/article117882467/Zalandokaempft-um-den-ersten-Platz-bei-Fashion.html (accessed: $28^{\text {th }}$ May 2019)

[31] Held, M., Graf, R., Wehner, D., Eckert, S., Faltenbacher, M., Weidner, S. and Braune, O. (2016), "Abschlussbericht: Bewertung der Praxistauglichkeit und Umweltwirkungen von Elektrofahrzeugen"

[32] Cox, B., Mutel, C. L., Bauer, C., Mendoza Beltran, A. and van Vuuren, D. P. (2018), "Uncertain Environmental Footprint of Current and Future Battery Electric Vehicles", Environmental science \& technology, Vol. 52, No. 8, pp. 4989-4995.

[33] DAT (2017), "DAT Report 2017", available at: www.dat.de/report (accessed: $28^{\text {th }}$ May 2019)

[34] Held, M. (2014), "Methodischer Ansatz und Systemmodell zur ökologisch-technischen Analyse zukünftiger Elektrofahrzeugkonzepte", $\mathrm{PhD}$ dissertation, Forschungsergebnisse aus der Bauphysik, Vol. 18, Fraunhofer-Verl., Stuttgart, Germany.

[35] thinkstep (1992-2019), "GaBi ts. Software-System and Databases for Life Cycle Engineering", Stuttgart, Echterdingen, Germany.

[36] Lindner, J.-P., Department for Life Cycle Engineering, Fraunhofer Institute for Building Physics IBP, Stuttgart, Germany.

[37] Universiteit Leiden - Institute of Environmental Sciences, "CMLIA Characterisation Factors", available at: https://www.universiteitleiden.nl/en/research/researchoutput/science/cml-ia-characterisation-factors (accessed: $28^{\text {th }}$ May 2019).

[38] Anagnostopoulou, E., Bothos, E., Magoutas, B., Schrammel, J. and Mentzas, G. (2018), "Persuasive Interventions for Sustainable Travel Choices Leveraging Users' Personality and Mobility Type", in Ham, J. et al. (Eds.), Persuasive Technology 2018 Proceedings of the 13th International Conference, PERSUASIVE 2018, Waterloo, ON, Canada.

[39] Hankammer, S., Weber, A. M., Canetta, L., Sel, S. K. and Hora, M. (2017), "A sustainability based optimization model for starting solutions in toolkits for mass customization", in Engineering, technology \& innovation management beyond 2020: new challenges, new approaches, 2017 Proceedings of the International Conference on Engineering, Technology and Innovation (ICE/ITMC) pp. 407-416.

[40] Held, M., Wehner, D., Hämmerl, R., Dangelmaier, M., Briem, A.K., Reiff, C. and Wulle, F. (2018), "Personalization in the Automotive and Building Sector - Research Program of the HighPerformance Center "Mass Personalization" in Stuttgart", in 2018 Proceedings of the 8th International Conference on Mass Customization and Personalization - Community of Europe (MCP-CE 2018), Novi Sad, Serbia.

[41] University of Stuttgart (2017), "Baden-Württemberg supports new centre of excellence for "Mass Personalization" at the Stuttgart location. Joint initiative by the University of Stuttgart and the Fraunhofer Institute for personalized products", Press release No. 092, 18.07.2017, available at: https://www.unistuttgart.de/en/university/news/press-release/NeuesLeistungszentrum-Mass-Personalization-am-Standort-Stuttgart/ (accessed: 28 ${ }^{\text {th }}$ May 2019) 